Corrigendum

\title{
Corrigendum to "Molecular Dynamics Simulation of Aggregates in the Dodecane/span80 System and Their Behaviour in an Electric Field"
}

\author{
Madhusoodanan Mannoor, Sangmo Kang, and Yong Kweon Suh \\ Department of Mechanical Engineering, Dong-A University, 840 Hadan-dong, Saha-gu, Busan 604-714, Republic of Korea \\ Correspondence should be addressed to Yong Kweon Suh; yksuh@dau.ac.kr
}

Received 23 May 2016; Accepted 9 June 2016

Copyright (C) 2016 Madhusoodanan Mannoor et al. This is an open access article distributed under the Creative Commons Attribution License, which permits unrestricted use, distribution, and reproduction in any medium, provided the original work is properly cited.

In the article titled "Molecular Dynamics Simulation of Aggregates in the Dodecane/span80 System and Their Behaviour in an Electric Field" [1], there was an error in the "Acknowledgments" section, which should be corrected as follows.

This work was supported by NRF Grant no. 2009-0083510 through Multi-Phenomena CFD Engineering Research Center and by the Human Resources Development of the Korea Institute of Energy Technology Evaluation and Planning (KETEP) grant funded by the Korean Government Ministry of Knowledge Economy (no. 20134010200550).

\section{References}

[1] M. Mannoor, S. Kang, and Y. K. Suh, "Molecular dynamics simulation of aggregates in the dodecane/span80 system and their behaviour in an electric field," Advances in Condensed Matter Physics, vol. 2015, Article ID 739458, 9 pages, 2015. 

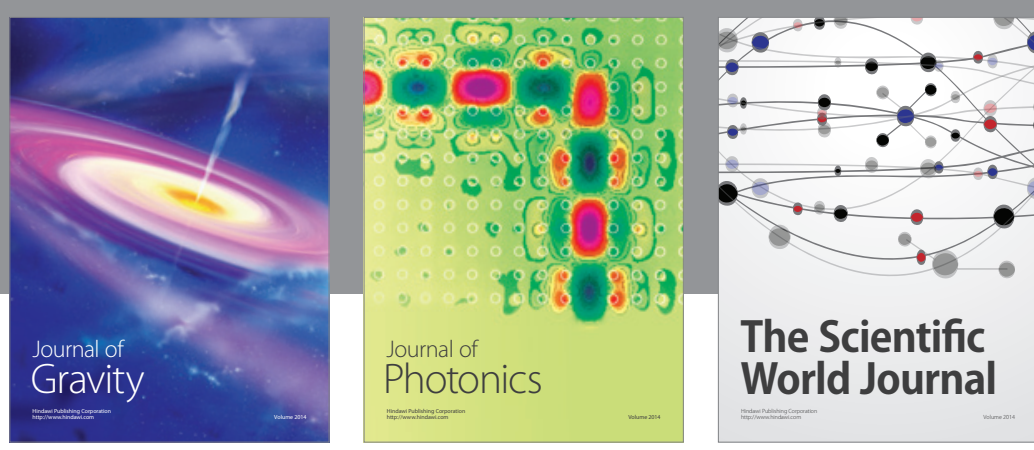

The Scientific World Journal
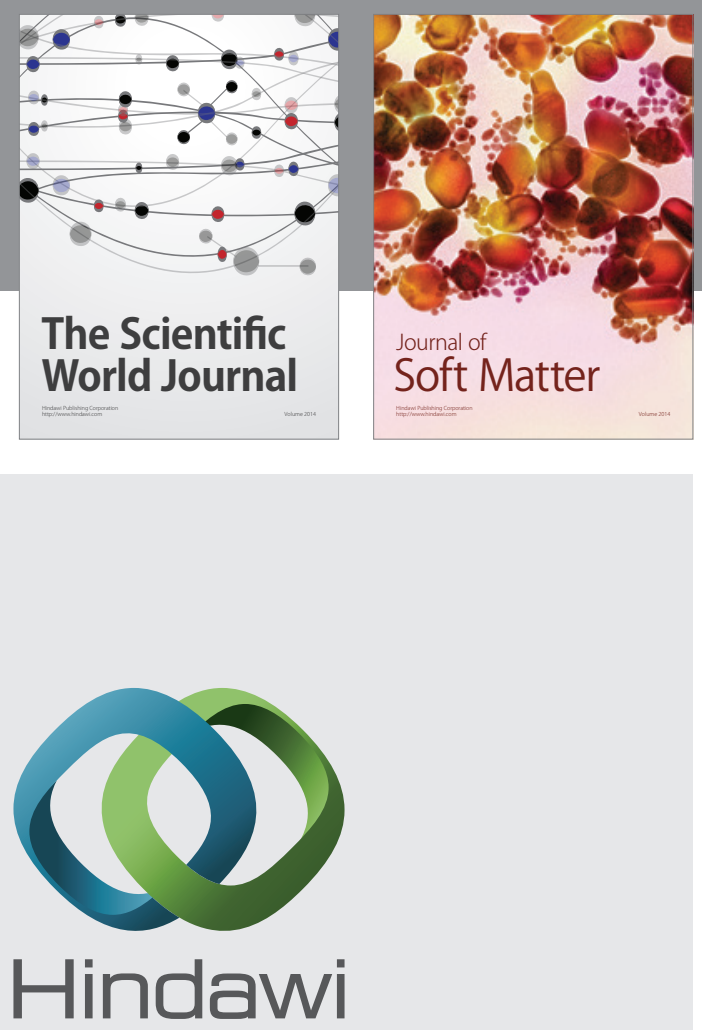

Submit your manuscripts at

http://www.hindawi.com

nternational Journal of

Statistical Mechanics
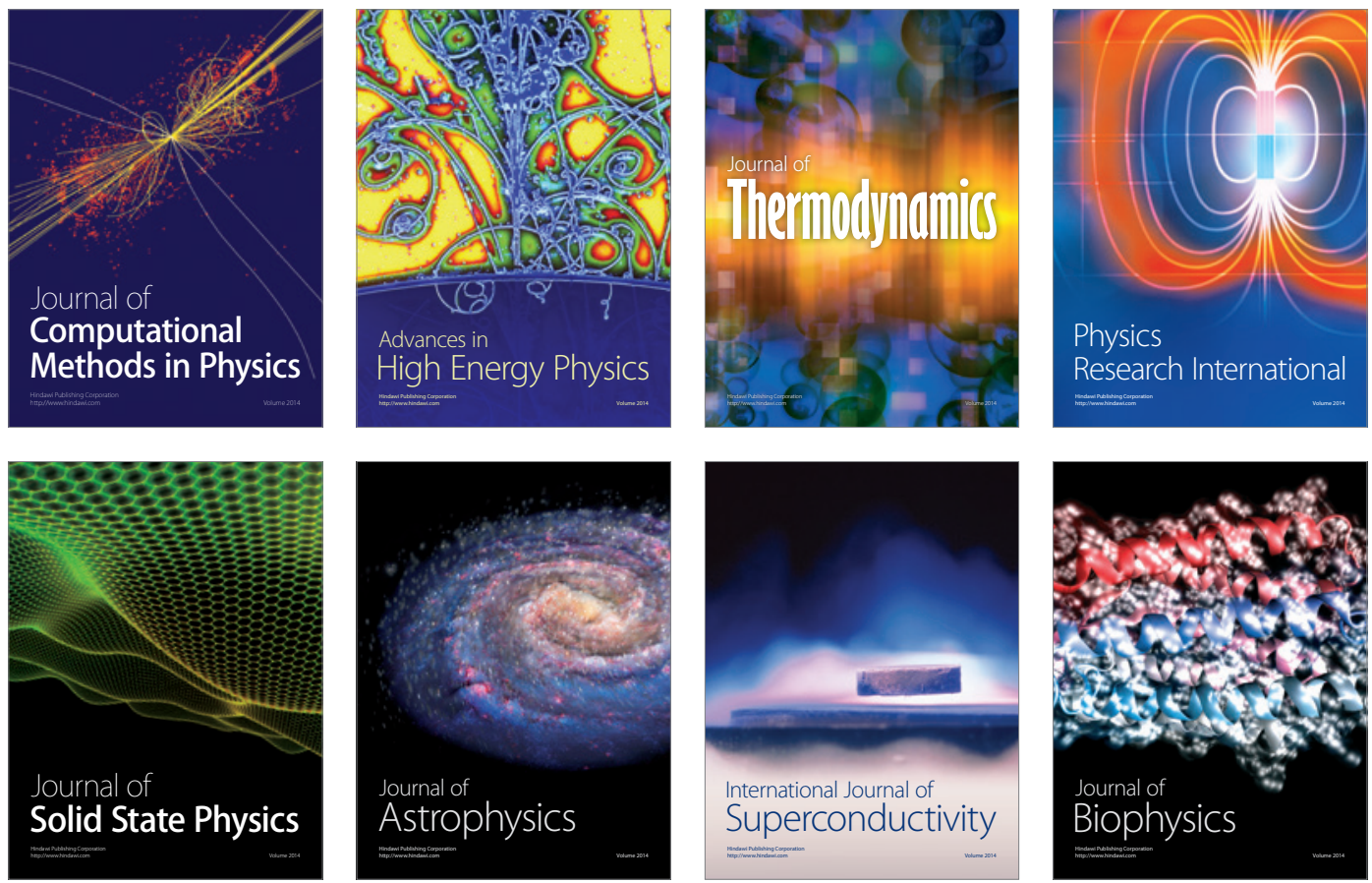
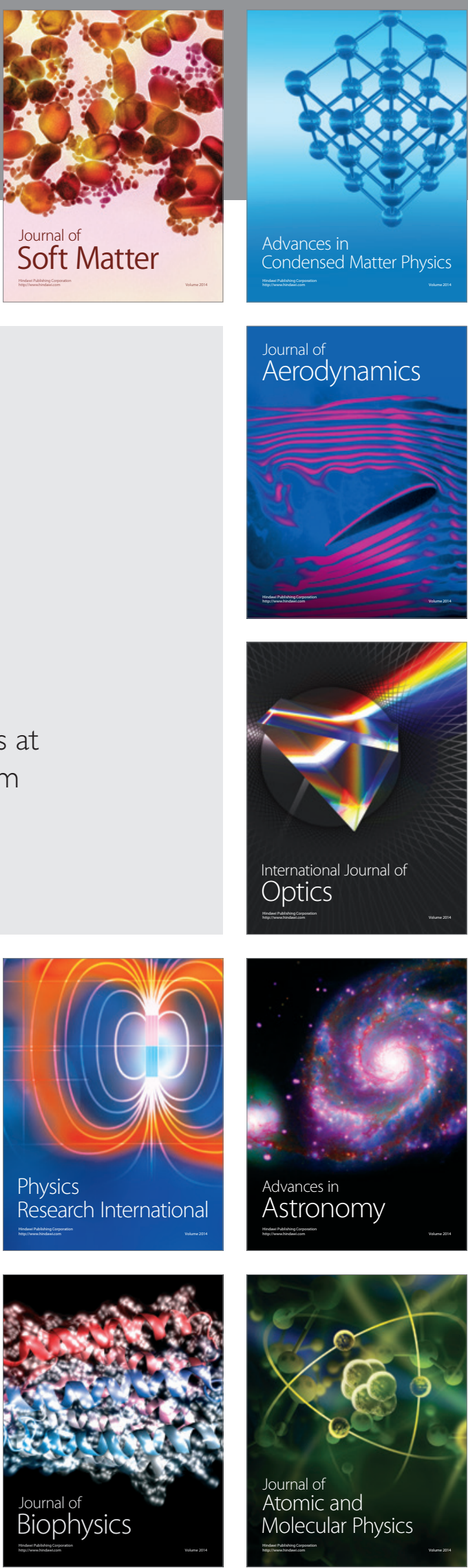